\title{
Extensive intragenic recombination and patterns of linkage disequilibrium at the CSN3 locus in European rabbit
}

\author{
Miguel CARNEIRO*, Nuno FERRAND \\ CIBIO, Centro de Investigação em Biodiversidade e Recursos Genéticos, \\ Campus Agrário de Vairão, 4485-661 Vairão, and \\ Departamento de Zoologia e Antropologia, Faculdade de Ciências da \\ Universidade do Porto, 4099-002 Porto, Portugal
}

(Received 30 August 2006; accepted 20 November 2006)

\begin{abstract}
Kappa-casein (CSN3) plays an important role in stabilising the Ca-sensitive caseins in the micelle. The European rabbit (Oryctolagus cuniculus) CSN3 has previously been shown to possess two alleles (A and B), which differ deeply in their intronic regions (indels of 100 and 1550 nucleotides in introns 1 and 4, respectively). Furthermore, a correlation between several reproductive performance traits and the different alleles was described. However, all these data were exclusively collected in rabbit domestic breeds, preventing a deeper understanding of the extensive polymorphism observed in the CSN3 gene. Additionally, the techniques available for the typing of both indel polymorphisms were until now not suitable for large-scale studies. In this report, we describe a simple, PCR-based typing method to distinguish rabbit CSN3 alleles. We analyse both ancient wild rabbit populations from the Iberian Peninsula and France, and the more recently derived English wild rabbits and domestic stocks. A new allele (C) showing another major indel $(250 \mathrm{bp})$ in intron 1 was found, but exclusively detected in Iberian wild rabbits. In addition, our survey revealed the occurrence of new haplotypes in wild populations, suggesting that intragenic recombination is important in creating genetic diversity at this locus. This easy and low cost single-step PCR-based method results in an improvement over previous described techniques, can be easily set up in a routine molecular laboratory and would probably be a valuable tool in the management of rabbit domestic breeds.
\end{abstract}

European rabbit / CSN3 gene / indel polymorphism / intragenic recombination / linkage disequilibrium

\section{INTRODUCTION}

In the last few years many studies focussing on the genetics and evolution of mammalian casein genes have been performed [24], and references therein.

\footnotetext{
*Corresponding author: miguel.carneiro@mail.icav.up.pt
} 
A major reason for this interest is the clear connection between genetic polymorphism at these genes and important production traits in a variety of domesticated species. K-casein (CSN3) is important in the stabilisation of milk micelles and evidence showing that its relative concentration versus other casein proteins varies among allelic variants within each species [20] has attracted large attention to this gene. Several biochemical and genetic studies, especially in cattle and goats, have shown a direct relationship between CSN3 and several manufacturing properties and digestibility of milk as well as antimicrobial activity e.g. $[5,8,11,18,21]$. Because of this, CSN3 has been the target of recent studies, namely in species of agronomic importance, as a possible candidate gene under artificial selection during the domestication process e.g. [17, 28].

Comparative studies reveal that caseins occur in a genomic cluster comprising between 250 and $350 \mathrm{~kb}$, and that its organisation and orientation is highly conserved among mammals [24]. In particular, the organisation of CSN3 is conserved in all species studied so far, suggesting a higher selective pressure on this gene than on other caseins [24]. Interestingly, a remarkable polymorphism was described by means of Southern blot analysis for the CSN3 locus in the European rabbit (Oryctolagus cuniculus), where two common alleles (CSN3*A and $C S N 3 * B$ ) differing in indels of 100 and 1550 nucleotides in introns 1 and 4, respectively, were found in individuals from rabbit domestic breeds [16]. The $C S N 3 * A$ allele possesses part of an inverted rabbit LINE (Long Interspersed Repeated Element) in the first intron, which is truncated in the $C S N 3 * B$ allele, and a direct LINE in the fourth intron that is absent in the $\operatorname{CSN} 3 * B$ allele (these alleles will be named hereafter as haplotypes A1A4 and B1B4, respectively) (Fig. 1). Despite the fact that no individuals from rabbit domestic breeds exhibiting chromosomes with only one deletion were found, the same authors suggested that such haplotypes could exist in other rabbit populations (e.g. old rabbit breeds or wild populations). In addition, no differences in the expression of both haplotypes in the mammary gland of lactating females were detected and the two haplotypes are translated into identical proteins [16]. Yet, a correlation between the CSN3 genotype and the breeding capacity of a New Zealand White rabbit stock has been found [3], where rabbits heterozygous at this locus perform better than both homozygous types and the more common allele, $C S N 3 * A$, performs better than the $C S N 3 * B$ allele.

While the Southern blot technique used by Hiripi et al. [16] effectively separated the rabbit CSN3 indel polymorphisms, its costs, dependent on large amounts of high quality DNA and time consuming aspects, are not appropriate for the development of more detailed investigations. Additionally, the fact that these data were exclusively collected in individuals from rabbit domestic 


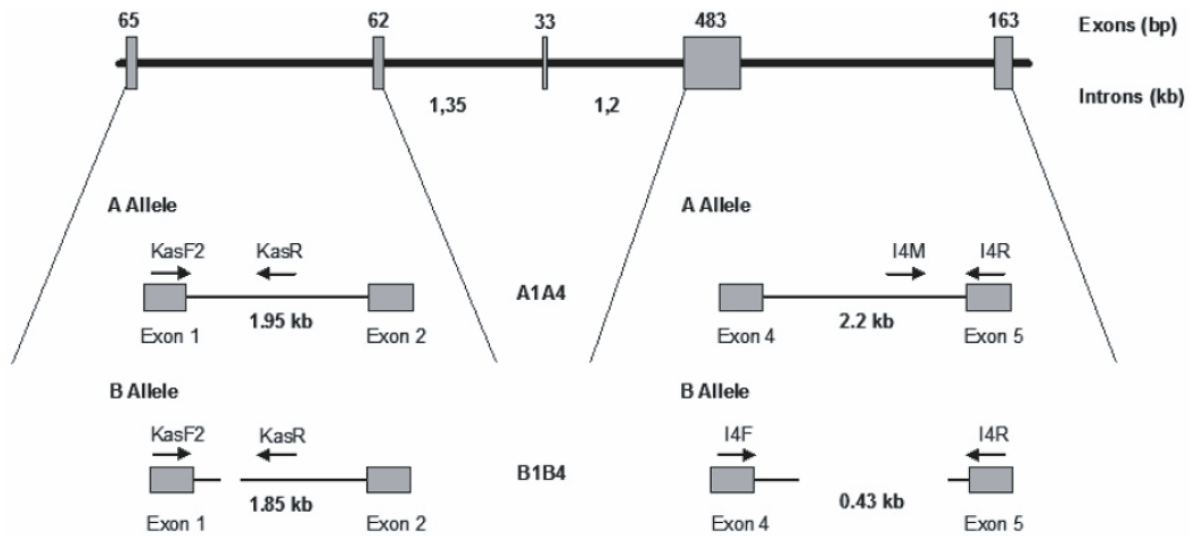

Figure 1. Schematic representation of the genomic structure of the rabbit CSN3 alleles. Exons are represented as boxes and introns as horizontal lines. Lengths of exons and introns are indicated above and below the horizontal line, respectively. Approximate positions of the indels are shown by gaps in the horizontal lines. The relative positions of the primers (KasF2, KasR, I4F, I4M and I4R) used for amplification are indicated.

breeds has hampered a deeper understanding of the extensive polymorphism observed at the CSN3 locus. In fact, rabbit domestication was probably accomplished during the Middle Ages [7] and contemporary domestic breeds did not originate before the 18th century [1]. Several population genetic studies have shown that rabbit domestic breeds are genetically very homogeneous and represent a small subset of the genetic diversity of the species at different levels of analysis: mitochondrial DNA sequence variation [4], microsatellites [23], protein electrophoretic polymorphisms [12] and immunogenetic markers [10]. In contrast, wild rabbit populations in their native distribution range, the Iberian Peninsula, revealed high levels of genetic diversity and the presence of two evolutionary divergent units, identified at both nuclear and cytoplasmic level $[2,13,14]$, that seem to correspond to the subspecies Oryctolagus cuniculus cuniculus and O.c. algirus, originally described on morphological grounds by Cabrera [6].

The primary aim of our work was to initiate a much broader study on the genetics and molecular evolution of the rabbit CSN3 polymorphism than those reported in previous publications. To accomplish this goal, we first developed a new simple and low cost technique for the typing of both indel polymorphisms at introns 1 and 4 (hereafter named CSN3I1 and CSN3I4, respectively), ideally suited for the screening of large numbers of samples. We then used this technique to analyse various domestic and wild rabbit populations and describe 
extensive intragenic recombination at the rabbit CSN3 locus as well as additional allelic variation.

\section{MATERIALS AND METHODS}

\subsection{Sampling}

We included five sources of DNA in this study: (i) 33 rabbits obtained from two domestic breeds (Fauve de Bourgogne and Champagne Argenté); (ii) 41 wild rabbits from the south-western Iberian Peninsula, included in the subspecies $O$. c. algirus; (iii) 44 wild rabbits from the north-eastern Iberian Peninsula, included in the subspecies $O$. c. cuniculus; (iv) 23 animals from two French wild rabbit populations; and (v) 26 individuals from an English wild rabbit population. All domestic breeds and Central European wild rabbit populations are included in the subspecies $O$. c. cuniculus.

\subsection{DNA amplification}

Genomic DNA was obtained from ear tissue following standard procedures. The PCR products were obtained using oligonucleotide primers, designed according to the rabbit CSN3 DNA sequence of CSN3I1 and CSN3I4 (Genbank accession number U44054 and U44057-58, respectively) with the exception of primer KasR that was designed after amplification and complete sequencing of CSN3I1 (Genbank accession number 2EF117310). The primers were KasF2 (5'-TCAACCTACTGCCAAGCAAG-3') and KasR (5'-CGTGGCTCAATAGGCTAATCCTC-3') for CSN3I1 and I4F2 (5'-GCATGATACCAAGGAACATCAA-3'), I4R2 (5'-CAGCTGCTGAAGAGTTTGAAGA-3') and I4M (5'-AGATCACCGTGGTGCGCCGACG-3') for CSN3I4. While for CSN3II we used two primers flanking the indel, the same approach was not possible in the case of CSN3I4 due to the large size differences between the two alleles described (Fig. 1). This situation resulted in a large asymmetry in the amplification of both $\operatorname{CSN} 3 I 4^{*} A$ and $C S N 3 I 4^{*} B$, and an internal primer (I4M) specific for the $\operatorname{CSN} 3 I 4^{*} A$ allele was needed. A touchdown PCR procedure was used for the amplification of both introns. PCR were performed in a 10- $\mu \mathrm{L}$ mixture containing $1 \mathrm{X}$ Ecotaq specific PCR buffer (Ecogen), $2.0 \mathrm{mM} \mathrm{MgSO}$, $0.4 \mathrm{mM}$ each dNTP, $0.2 \mathrm{mM}$ primer and $1 \mathrm{U}$ of Ecotaq DNA polymerase. For CSN3II the PCR protocol consisted of two phases. Phase 1 included an initial step of $92^{\circ} \mathrm{C}$ for $2 \mathrm{~min}$, followed by 10 cycles of 
denaturation at $92{ }^{\circ} \mathrm{C}$ for $25 \mathrm{~s}$, annealing at variable temperatures for $25 \mathrm{~s}$, and extension at $72{ }^{\circ} \mathrm{C}$ for $40 \mathrm{~s}$. Annealing temperature was set to $65^{\circ} \mathrm{C}$ in the first cycle and then decreased $1.0^{\circ} \mathrm{C}$ at each of the 10 subsequent cycles. Phase 2 consisted of 25 cycles of $94{ }^{\circ} \mathrm{C}$ for $25 \mathrm{~s}, 52{ }^{\circ} \mathrm{C}$ for $25 \mathrm{~s}$, and $72{ }^{\circ} \mathrm{C}$ for $40 \mathrm{~s}$. The CSN3I4 PCR protocol consisted of phase 1, with an initial step of $92{ }^{\circ} \mathrm{C}$ for $2 \mathrm{~min}$, followed by 10 cycles of denaturation at $92{ }^{\circ} \mathrm{C}$ for $25 \mathrm{~s}$, annealing at variable temperatures for $25 \mathrm{~s}$, and extension at $72{ }^{\circ} \mathrm{C}$ for $40 \mathrm{~s}$. Annealing temperature was set at $60{ }^{\circ} \mathrm{C}$ in the first cycle and then decreased at each of the 10 subsequent cycles by $0.5{ }^{\circ} \mathrm{C}$ down to $55.5{ }^{\circ} \mathrm{C}$. Phase 2 consisted of 25 cycles of $92{ }^{\circ} \mathrm{C}$ for $25 \mathrm{~s}, 48^{\circ} \mathrm{C}$ for $25 \mathrm{~s}$, and $72{ }^{\circ} \mathrm{C}$ for $40 \mathrm{~s}$. PCR products were visualised in $2 \% \mathrm{p} / \mathrm{v}$ agarose gels.

\subsection{Data analysis}

Allele frequencies at both CSN3I1 and CSN3I4 were calculated by gene counting. Statistical analyses for testing Hardy-Weinberg equilibrium were assessed by a modified version of the exact test described by Guo and Thompson [15]. Our data set consisted of two loci genotypes with unknown phase in multiple heterozygous individuals. However, the investigation of linkage disequilibrium requires knowledge about the underlying haplotype frequencies. To accomplish this, we carried out haplotype frequency estimation using a Maximum-likelihood approach that implements an expectation-maximisation algorithm [9]. Linkage disequilibrium was assessed by a likelihood ratio test whose distribution was obtained by permutation [26]. The relative amounts of association between the alleles at CSN3II and CSN3I4 were quantified by $\left|D^{\prime}\right|$ [19]. $\left|D^{\prime}\right|$ is the standardised disequilibrium value that takes the usual disequilibrium coefficient $\mathrm{P}\left(\mathrm{A}_{i} \mathrm{~B}_{j}\right)-\mathrm{P}\left(\mathrm{A}_{i}\right) \mathrm{P}\left(\mathrm{B}_{j}\right)$ and divides it by its maximal possible value. Values range from 0 to 1 , with 0 reflecting perfect independence between the alleles compared at the two loci and 1 reflecting complete linkage disequilibrium. All the analyses were done using the ARLEQUIN software package [25].

\section{RESULTS AND DISCUSSION}

Our amplification technique resulted in clear band patterns for both indel polymorphisms at rabbit CSN3II and CSN3I4 that are shown in Figure 2. PCR products for $C S N 3 I 1$ were 755 bp for the $C S N 3 I 1^{*} \mathrm{~A}$ allele and $646 \mathrm{bp}$ for the $C S N 3 I 1 * \mathrm{~B}$ allele. In addition, a new variant - here called the $C S N 3 I{ }^{*} \mathrm{C}$ allele - was also identified and resulted in a PCR product of $513 \mathrm{bp}$. This PCR 

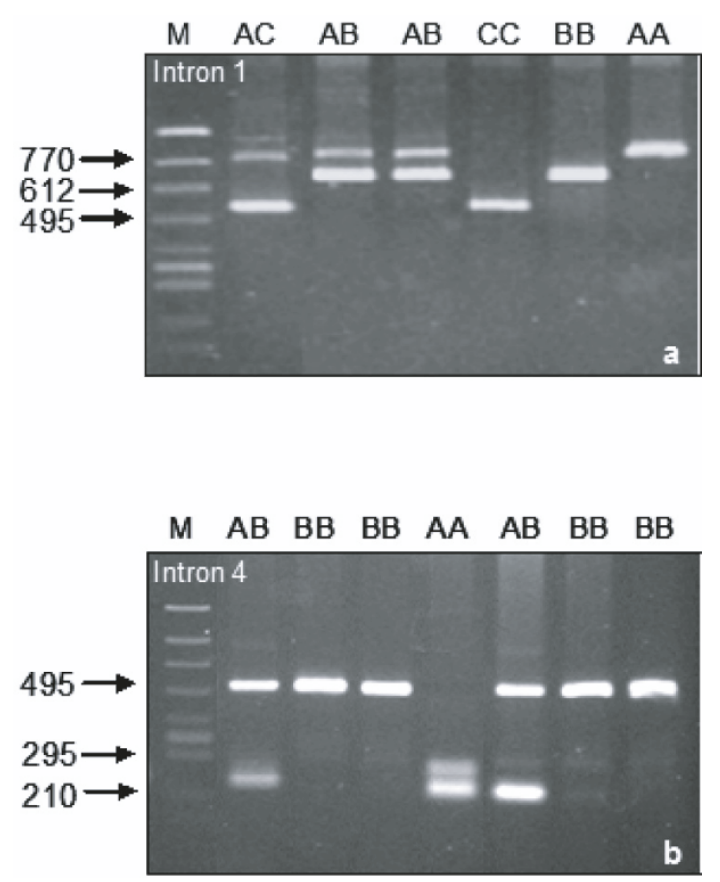

Figure 2. Observed genotypes of European rabbit CSN3II (a) and CSN3I4 (b) after agarose gel electrophoresis $(2 \% \mathrm{p} / \mathrm{v})$. Genotypes of individuals are indicated above the lanes. The DNA size marker (M) used is in the left lane of both pictures, and relevant fragment sizes are given. PCR products for CSN3I1 (a) were $755 \mathrm{bp}$ for the A allele, $646 \mathrm{bp}$ for the B allele and $511 \mathrm{bp}$ for the $\mathrm{C}$ allele. PCR products for CSN3I4 (b) were $230 \mathrm{bp}$ for the A allele and $508 \mathrm{bp}$ for the B allele.

product was sequenced (Genbank accession number EF117311) and revealed a deletion that is wider (244 bp) than the one previously described for the $\operatorname{CSN} 3 I 1 * B$ allele in both ends (Fig. 3). PCR products for CSN3I4 were $230 \mathrm{bp}$ for the $C S N 3 I 4^{*} \mathrm{~A}$ allele and 508 bp for the $\operatorname{CSN} 314^{*} \mathrm{~B}$ allele, and no additional variation was found. The amplification techniques described in this work seem to be a significant improvement over existing methods for the study of rabbit CSN3 genetic polymorphisms because of the following: (i) PCR methods are highly reproducible due to the small size of amplified fragments; and (ii) differences in allele size are easily resolved after routine agarose gel electrophoresis.

The two indel polymorphisms previously described by Hiripi et al. [16] at the CSN3II and CSN3I4 were found in the five groups of rabbit populations (that include both wild and domestic animals) analysed in this work, while the new allelic form $\left(\operatorname{CSN} 3 I 1^{*} \mathrm{C}\right)$ was exclusively detected in $O$. c. algirus populations. Allelic frequency distributions of $\mathrm{A}$ and $\mathrm{B}$ alleles at both CSN3II 


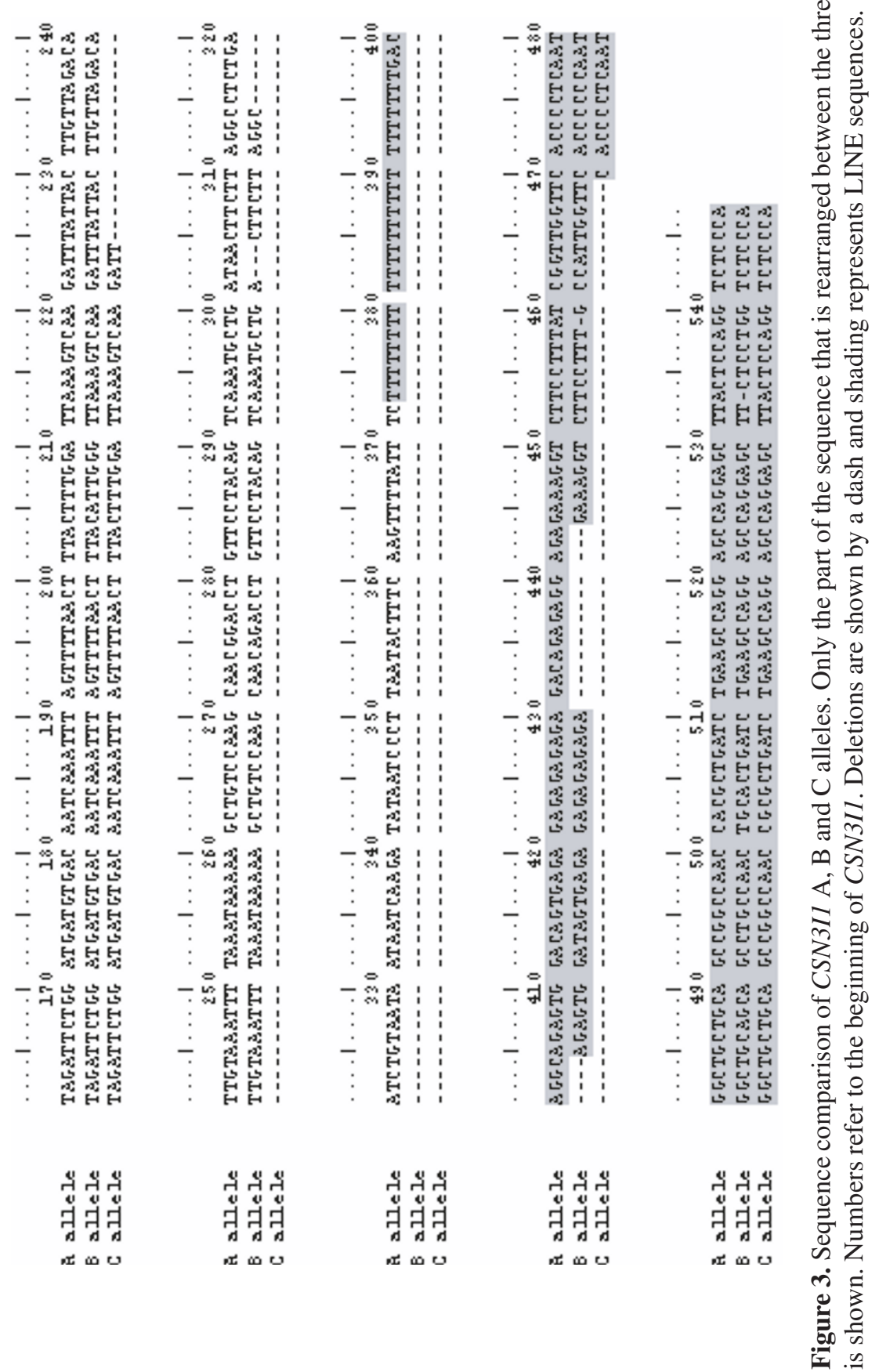


Table I. Allelic frequencies at the CSN3II and CSN3I4 in six wild and domestic rabbit populations.

\begin{tabular}{cccccc}
\hline & \multicolumn{2}{c}{ Intron 1 alleles } & \multicolumn{2}{c}{ Intron 4 alleles } \\
\hline & $\mathbf{A}$ & $\mathbf{B}$ & $\mathbf{C}$ & $\mathbf{A}$ & $\mathbf{B}$ \\
\hline Domestic $^{1}$ & $0.758 \pm 0.053$ & $0.242 \pm 0.053$ & 0 & $0.758 \pm 0.052$ & $0.242 \pm 0.052$ \\
$\begin{array}{c}\text { Iberian Peninsula } \\
(\boldsymbol{O} \text {. } \text { c. } \text { cuniculus })^{2}\end{array}$ & $0.807 \pm 0.042$ & $0.193 \pm 0.042$ & 0 & $0.716 \pm 0.048$ & $0.284 \pm 0.048$ \\
$\begin{array}{c}\text { Iberian Peninsula } \\
\left(\text { O. } \text { c. }{\text { algirus })^{3}}^{3}\right.\end{array}$ & $0.605 \pm 0.053$ & $0.372 \pm 0.052$ & $0.023 \pm 0.002$ & $0.640 \pm 0.051$ & $0.360 \pm 0.051$ \\
France $^{4}$ & $0.891 \pm 0.046$ & $0.109 \pm 0.046$ & 0 & $0.891 \pm 0.046$ & $0.109 \pm 0.046$ \\
England $^{5}$ & $0.250 \pm 0.060$ & $0.750 \pm 0.050$ & 0 & $0.385 \pm 0.067$ & $0.615 \pm 0.067$ \\
$\begin{array}{c}\text { New Zealand } \\
\text { White }\end{array}$ & $0.712 \pm 0.056$ & $0.288 \pm 0.056$ & 0 & $0.712 \pm 0.056$ & $0.288 \pm 0.056$ \\
(Domestic) $^{6}$ & & & & & \\
\hline
\end{tabular}

${ }^{1}$ Includes individuals from Fauve de Bourgogne and Champagne Argenté breeds.

${ }^{2}$ Samples were collected near Alicante, Peralta, Tarragona and Lérida (eastern Iberian Peninsula).

${ }^{3}$ Samples were collected near Tavira, Vila Real and Guarda (western Iberian Peninsula).

${ }^{4}$ Samples were collected near Perpignan and Versailles (France).

${ }^{5}$ Samples were collected near Winchester (Southern England).

${ }^{6}$ Data from Hiripi et al. [16].

and CSN3I4 are similar in Iberian/French wild and domestic populations, with the A allele always being the more common allele (Tab. I). In contrast, English wild rabbits show a higher proportion of the B allele in both CSN3II and CSN3I4. To the exception of this population, our results were in close agreement with those reported by Hiripi et al. [16] for two different stocks belonging to the New Zealand White breed (Tab. I). No significant departures from Hardy-Weinberg expectations were detected in wild rabbit samples from Iberia and France, while a significant heterozygous deficit occurred in both English wild rabbits and domestic breeds (data not shown). The inclusion of related individuals in our samples together with the relatively small population size of both English wild and domestic breed populations are possible explanations for this observation.

In Table II we present haplotype frequency estimates, probability values from linkage disequilibrium tests and $\left|D^{\prime}\right|$ values reflecting the non-random association between alleles at CSN3I1 and CSN3I4. We did not consider the $\operatorname{CSN} 3 I{ }^{*} \mathrm{C}$ allele in this analysis because it was detected in very low frequencies only in the $O$. c. algirus population. The simple inspection of this table shows the widespread occurrence of the four haplotypes (A1A4, B1B4, A1B4 
Table II. Haplotype frequency estimates, probability values from linkage disequilibrium tests $(p)$ and linkage disequilibrium values (|D'|) for CSN3II and CSN3I4 for five groups of wild and domestic rabbits.

\begin{tabular}{ccccccc}
\hline & A1A4 & B1B4 & A1B4 & B1A4 & $\boldsymbol{p}$ & $\left|\mathbf{D}^{\prime}\right|$ \\
\hline Domestic $^{1}$ & $0.758 \pm 0.053$ & $0.242 \pm 0.053$ & 0 & 0 & 0 & 1.0000 \\
Iberian Peninsula $^{2}$ & & & & & & \\
$\left(\begin{array}{l}\text { O. } \text { c. } \text { cuniculus }) \\
\text { berian Peninsula }\end{array}\right.$ & $0.612 \pm 0.055$ & $0.089 \pm 0.035$ & $0.195 \pm 0.047$ & $0.104 \pm 0.037$ & $0.31 \pm 0.001$ & 0.2605 \\
$\left(\begin{array}{l}\text { O. } \text { c. } \text { algirus })^{3} \\
\text { France }^{4}\end{array}\right.$ & $0.396 \pm 0.060$ & $0.164 \pm 0.049$ & $0.214 \pm 0.053$ & $0.226 \pm 0.054$ & $0.65 \pm 0.001$ & 0.0477 \\
England $^{5}$ & $0.845 \pm 0.054$ & $0.063 \pm 0.036$ & $0.046 \pm 0.032$ & $0.046 \pm 0.032$ & $0.005 \pm 0.0002$ & 0.5512 \\
\hline
\end{tabular}

\footnotetext{
${ }^{1}$ Includes individuals from Fauve de Bourgogne and Champagne Argenté breeds.

${ }^{2}$ Samples were collected near Alicante, Peralta, Tarragona and Lérida (eastern Iberian Peninsula).

${ }^{3}$ Samples were collected near Tavira, Vila Real and Guarda (western Iberian Peninsula).

${ }^{4}$ Samples were collected near Perpignan and Versailles (France).

${ }^{5}$ Samples were collected near Winchester (Southern England).
}

and B1B4) in wild rabbit populations (only in the English sample haplotype A1B4 is not present), suggesting the occurrence of intragenic recombination at the rabbit CSN3 locus. In contrast, our domestic rabbit sample, originated from the breeds Fauve de Bourgogne and Champagne Argenté, shows only haplotypes A1A4 and B1B4, in accordance with the results of Hiripi et al. [16]. Taken together, our results not only confirm the initial prediction of Hiripi et al. [16] that chromosomes with only one rearranged region do exist in more ancient populations (e.g. wild rabbits), but also add to recently published data suggesting that rabbit domestic breeds harbour a small subset of the genetic diversity present in natural populations of this species [10,12,13,23].

The analysis of linkage disequilibrium is also very informative in our set of populations. In Iberia, all four haplotypes were found and the association between alleles at the two introns is not statistically significant, suggesting that despite the short $5 \mathrm{~kb}$ of sequence that separates CSN3I1 and CSN3I4, extensive intragenic recombination coupled with the long term persistence of the populations in the region is sufficient to generate a situation of linkage equilibrium. In contrast, a significant value of linkage disequilibrium and a higher value of |D'| was observed for the French wild rabbit populations, a finding that agrees well with a scenario of a relatively recent post-glacial colonisation of this region [22]. Finally, both the English wild rabbit sample and the domestic breeds exhibited $\left|D^{\prime}\right|$ values of 1 , indicative of complete linkage disequilibrium. These results are nicely consistent with (i) the recent introduction of 
the European rabbit in Great Britain during the XII century [27]; and (ii) the even more recent domestication of the rabbit, most probably accomplished in the late XV century [7].

In conclusion, our new methodology for typing the length variation observed at the rabbit CSN3I1 and CSN3I4 can be easily applied in large scale studies and results in a clear simplification over previously described methods. Additionally, the investigation of CSN3 indel polymorphisms together with a linkage disequilibrium analysis in both ancient wild rabbit populations from the Iberian Peninsula and France and the more recently derived English wild rabbits and domestic stocks revealed the occurrence of new haplotypes resulting from intragenic recombination and a newly discovered deletion at CSN3II (haplotype C1A4). Future studies in our laboratories will address questions related with the evolutionary relationships between the CSN3 haplotypes and their patterns of nucleotide diversity in a functional relevant gene that has been identified as a target of selection in rabbits [3] and other mammals [24,29].

\section{ACKNOWLEDGEMENTS}

This work was partly supported by Fundação para a Ciência e a Tecnologia (SFRH/BD/23786/2005 Ph.D. grant to MC and research projects POCTI/BSE/40280/2001 and POCI/CVT/61590/2004). We thank R. Villafuerte and S. Moreno for help in collecting Spanish rabbit samples, D. Cowan for sending the English rabbit sample, and P.J. Esteves for valuable discussions.

\section{REFERENCES}

[1] Arnold J., Historique de l'élevage du lapin, C. R. Acad. Agric., France 80 (1994) 3-12.

[2] Biju-Duval C., Ennafaa H., Dennebouy N., Monnerot M., Mignotte F., Soriguer R., El Gaaïed A., El Hili A., Mounolou J.-C., Mitochondrial DNA evolution in lagomorphs: origin of systematic heteroplasmy and organization of diversity in European rabbits, J. Mol. Evol. 33 (1991) 92-102.

[3] Bösze Z., Hiripi L., Virág G., Tóth S., Makovics F., Fontaine M.L., Devinoy E., Polymorphism of the rabbit kappa casein gene and its influence on performance traits, Pflugers. Arch. 439 (2000) R2-R3.

[4] Branco M., Ferrand N., Monnerot M., Phylogeography of the European rabbit (Oryctolagus cuniculus) in the Iberian Peninsula inferred from RFLP analysis of the cytochrome b gene, Heredity 85 (2000) 307-317. 
[5] Brophy B., Smolenski G., Wheeler T., Wells D.L., Huillier P., Laible G., Cloned transgenic cattle produce milk with higher levels of beta-casein and kappacasein, Nature Biotechnol. 21 (2003) 157-162.

[6] Cabrera J., Fauna Ibérica, Museo Nacional de Ciências Naturales de Madrid, Madrid, 1914.

[7] Callou C., De la garenne au clapier. Étude archéozoologique du lapin en Europe occidentale, Mémoires du Muséum National d'Histoire Naturelle, Paris, 2003.

[8] Clark A.J., Prospects for the genetic engineering of milk, J. Cell Biochem. 49 (1992) 121-127.

[9] Dempster A.P., Laird N.M, Rubin D.B., Maximum likelihood from incomplete data via the EM algorithm, J. R. Statist. Soc., Series B 34 (1977) 1-38.

[10] Esteves P.J., Lanning D., Ferrand N., Knight K.L., Zhai S.-K., van der Loo W., Allelic variation at the $V_{H}$ a locus in natural populations of rabbit (Oryctolagus cuniculus L.), J. Immunol. 172 (2004) 1044-1053.

[11] Falaki M., Prandi A., Corradini C., Sneyers M., Gengler N., Massart S., Fazzini U., Burny A., Portetelle D., Renaville R., Relationships of growth hormone gene and milk protein polymorphisms to milk production traits in Simmental cattle, J. Dairy Res. 63 (1997) 47-56.

[12] Ferrand N., Branco M., The evolutionary history of the European rabbit (Oryctolagus cuniculus): Major patterns of population differentiation and geographic expansion inferred from protein polymorphism, in: Weiss S. and Ferrand N. (Eds.), Phylogeography of European Refugia, Springer (2006).

[13] Geraldes A., Rogel-Gaillard C., Ferrand N., High levels of nucleotide diversity in the European rabbit (Oryctolagus cuniculus) SRY gene, Anim. Genet. 36 (2005) 349-351.

[14] Geraldes A., Ferrand N., Nachman M., Contrasting patterns of introgression at $\mathrm{X}$ chromosome loci across a hybrid zone: The European rabbit (Oryctolagus cuniculus) case, Genetics 173 (2006) 919-933.

[15] Guo S.W., Thompson E.A., Performing the exact test of Hardy-Weinberg proportions for multiple alleles, Biometrics 48 (1992) 361-372.

[16] Hiripi L., Devinoy E., Rat P., Baranyi M., Fontaine M.L., Bösze Z., Polymorphic insertions/deletions of both 1550nt and 100nt in two microsatellite-containing, LINE-related intronic regions of the rabbit $\kappa$-casein gene, Gene 213 (1998) 2330.

[17] Jann O., Prinzenberg E.M., Luikart G., Caroli A., Erhardt G., High polymorphism in the $\kappa$-casein $(C S N 3)$ gene from wild and domestic caprine species revealed by DNA sequencing, J. Dairy Res. 71 (2004) 188-195.

[18] Kamiński S., Brym P., Ruść A., Wójcik E., Ahman A., Mägi R., Associations between milk performance traits in Holstein cows and 16 candidate SNPs identified by arrayed primer extension (APEX) microarray, Anim. Biotechnol. 17 (2006) $1-11$.

[19] Lewontin R.C., The interaction of selection and linkage. I. General considerations; heterotic models, Genetics 49 (1964) 49-67. 
[20] Lodes A., Krause I., Buchberger J., Aumann J., Klostermeyer H., The influence of genetic variants of milk proteins on the compositional and technological properties of milk. Casein micelle size and the content of non-glycosylated kappacasein, Milchwissenschaft 51 (1996) 368-373.

[21] Malkoski M., Dashper S.G., O’Brien-Simpson N.M., Talbo G.H., Macris M., Cross K.J., Reynolds E.C., Kappacin, a novel antibacterial peptide from bovine milk, Antimicrob. Agents Chemother. 45 (2001) 2309-2315.

[22] Queney G., Ferrand N., Weiss S., Mougel F., Monnerot M., Stationary distributions of microsatellite loci between divergent population groups of the European rabbit (Oryctolagus cuniculus), Mol. Biol. Evol. 18 (2001) 2169-2178.

[23] Queney G., Vachot A.M., Brun J.M., Dennebouy N., Mulsant P., Monnerot M., Different levels of human intervention in domestic rabbits: effects on genetic diversity, J. Hered. 93 (2002) 205-209.

[24] Rijnkels M., Multi-species comparison of the casein gene loci and evolution of the casein gene family, J. Mammary Gland Biol. Neoplasia 7 (2002) 327-345.

[25] Schneider S., Roessli D., Excoffier L., Arlequin: a software program for population genetics data analysis. Genetics and Biometry Lab, Department of Anthropology, University of Geneva (2000).

[26] Slatkin M., Excoffier L., Testing for linkage disequilibrium in genotypic data using the EM algorithm, Heredity 76 (1996) 377-383.

[27] Thompson H.V., The rabbit in Britain, in: Thompson H.V., King C.M. (Eds.), The European Rabbit, Oxford Science Publications, Oxford, 1994.

[28] Tsiaras A.M., Bargouli G.G., Banos G., Boscos C.M., Effect of kappa-casein and beta-lactoglobulin loci on milk production traits and reproductive performance of Holstein cows, J. Dairy Sci. 88 (2005) 327-334.

[29] Ward T.J., Honeucutt R.L., Derr J.N., Nucleotide sequence evolution at the $\kappa$-casein locus: evidence for positive selection within the family bovidae, Genetics 147 (1997) 1863-1872. 